\title{
The Relationship between X-Ray Stress Measured Value and Applied Stress in Elastic/Plastic Deformation Region in Tensile Testing
}

Masashi Nakashiro ${ }^{1 a^{*}}, Y$ Yasuhiro Takaku ${ }^{2 b}$, Yukinori Mitani ${ }^{2 c}$, and Ami Kohri ${ }^{2 d}$

${ }^{1} \mathrm{IHI}$ Inspection \& Instrumentation Co., Ltd. (IIC), 25-3, Minami-Ohi 6-chome, Shinagawa-ku, Tokyo 140-0013 Japan

${ }^{2} \mathrm{IHI}$ Inspection \& Instrumentation Co., Ltd. (IIC), 6-17, Fukuura 2-chome, Kanazawa-ku, Yokohama-city, Kanagawa 236-0004 Japan

a m_nakashiro@iic.ihi.co.jp, by_takaku@iic.ihi.co.jp,

cy_mitani@iic.ihi.co.jp, da_kohri@iic.ihi.co.jp

Keywords: X-Ray Residual Measurement, $\operatorname{Sin}^{2} \Psi$, True Stress, Elastic Strain, Plastic Strain

Abstract. Recently in Japan, the 2D detector X-ray stress measurement equipment has developed, and requests of on-site measuring the stress on structural components are increasing. On the other hand, high residual stress, which exceeds its tensile strength stress, is often observed on welded construction parts, and sometimes it causes defects or damage. We report a result of clarified characteristics of X-ray diffraction stress value (XRD) in which exceeds the yield point in the plastic strain region on steel (SM490) and stainless steel (SUS316). For studying the correlation with XRD measurement results and the stress value, we installed flat plate test specimens in the tensile test machine and cyclically loaded to the plastic strain region to simulate the welding structure under load. The XRD measurement values indicated a high correlation with the actual stress value. These results confirm that the XRD measurement values give the actual stress condition of the material under load, irrespective of elastic-plastic deformation. XRD measurement is not only applicable for measuring internal stress but also measuring combination of internal and external stress on a material. Consequently, XRD measurement can also be used to measure the loaded stress conditions of a structure (this stress is also called dead load or static load). Moreover, this outcome expands function of XRD from a specialized measuring method for residual stress to various structural conditions.

\section{Introduction}

To evaluate the validity of result by X-ray diffraction (XRD) measured residual stress, it is often used comparison with mechanical stress by 4-bend testing. This method is also used as measurement of X-ray elastic constants ${ }^{1}$. X-ray itself measures stress which dwells on fairly surface, so the residual stress value measured by XRD and mechanical stress value by 4-bend testing shows a high correlation when the specimen is in elastic region. However, measuring welded, heat treated, peened, or other surface treated parts are common demands in field measurement. Usually, there are yield point exceed high residual stress in these processed parts. The tensile test machine is used to produce the uniform deformation in the sample to evaluate the plastic deformation by XRD. Also, it is known that there are difference between the XRD measured value and the mechanical stress value in the plastic region. This difference occurs by influences of surface effect and phase stress ${ }^{2), 3}$.

This research describes the correlation between XRD measured stress and mechanical stress from the elastic to plastic strain range. We calculated nominal stress value by XRD measured stress value and load value of tensile test and true stress value by specimen elongation. 


\section{Experimental Materials and Method}

\subsection{Experimental Materials}

For testing, we chose the carbon steel (JIS: SM490) specimen which has a yield point and the stainless steel (JIS: SUS316) which does not have a yield point. We determined elastic region of the carbon steel as up to the yield point and the stainless steel as up to $0.2 \%$ of proof stress. Table 1 shows the sample material chemical compositions, mechanical properties and manufacturing process. These material's grain size are small more than ASTM E112 Plate IV No.5 and suit XRD stress measurement. Fig.1 shows the shape and dimensions of specimen.

Table 1 Material properties of test sample by mill sheet

\begin{tabular}{|c|c|c|c|c|c|c|c|c|c|c|c|}
\hline \multirow{3}{*}{$\begin{array}{l}\text { Material } \\
\text { (JIS) }\end{array}$} & \multicolumn{8}{|c|}{ Chemical compositions } & \multicolumn{3}{|c|}{ Mechanical properties } \\
\hline & $\mathrm{C}$ & $\mathrm{Si}$ & $\mathrm{Mn}$ & $\mathrm{P}$ & $S$ & $\mathrm{Ni}$ & $\mathrm{Cr}$ & Mo & $\begin{array}{c}\text { Yield strength/ } \\
0.2 \% \text { proof strength }\end{array}$ & $\begin{array}{l}\text { Tensile } \\
\text { strength }\end{array}$ & Elongation \\
\hline & \multicolumn{8}{|c|}{$\mathrm{Wt} \%$} & \multicolumn{2}{|l|}{$(\mathrm{MPa})$} & $(\%)$ \\
\hline $\begin{array}{l}\text { Carbon steel } \\
(\text { SM490) }\end{array}$ & 0.17 & 0.33 & 1.37 & 0.014 & 0.003 & & & & 418 & 541 & 26 \\
\hline $\begin{array}{c}\text { Stainless steel } \\
\text { (SUS316) }\end{array}$ & 0.04 & 0.46 & 0.84 & 0.028 & 0.001 & 10.06 & 16.08 & 2.09 & 337 & 601 & 56 \\
\hline
\end{tabular}

SM490: Hot rolling plate,

SUS316: Solution treatment

We determined the gauge length of extensometer as $50 \mathrm{~mm}$. For measuring by XRD, influence of residual stress which occurred while fabrication process of specimens should be removed. Therefore, we electrolytic polished the center parts of specimens, where to XRD measuring, for $6 \mathrm{~mm}$ diameter circle with depth of $0.15 \mathrm{~mm}$.

\subsection{Experimental method}

For mechanical test, we used $100 \mathrm{kN}$ screw load type tensile test machine. The measurement items were load-sell of tensile machine, XRD equipment, strain gauge, and extension meter. The strains were measured by strain gauges in elastic region and extensometer in plastic strain. The applied stress were calculated by the load divided by specimen cross area. Fig. 2 shows the experimental status on tensile test machine. For measuring the stress in

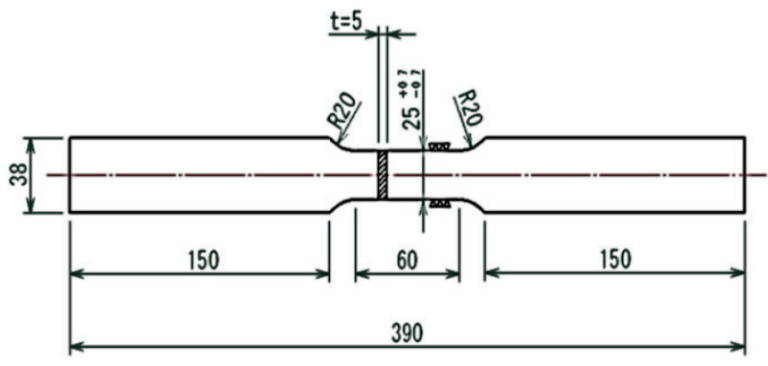

Fig. 1 Test specimen shape and dimension elastic region, we stopped the cross head of the testing machine when it gains the predefined stress point. Then we measured the stress by XRD with keeping cross head position and strain by strain gauge. For measuring the stress in plastic deformation area, we stopped the cross head when the load of testing machine was stabilized. Then we measured the stress by XDR, elongation and load. For
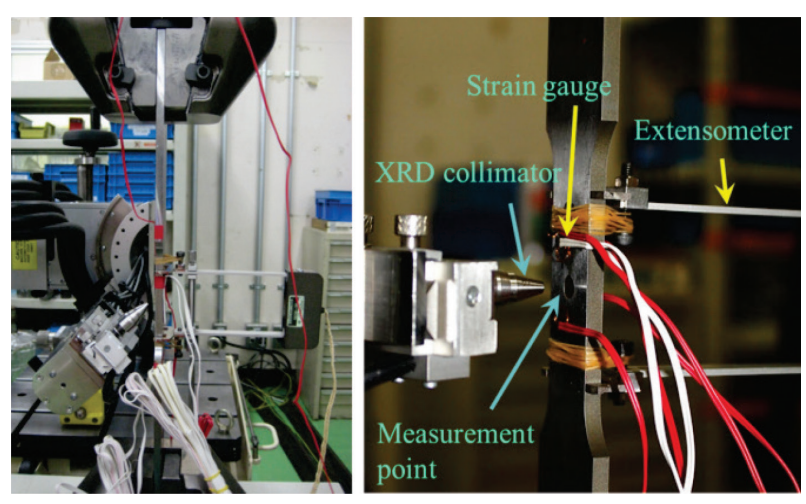
loading methods, we used incremental load method and cyclically load method.

1) Elastic strain: $\varepsilon_{\mathrm{e}}=\sigma / \mathrm{E}$ Plastic deformation: $\varepsilon_{\mathrm{p}}=\varepsilon_{\mathrm{e}}=\varepsilon \sigma / \mathrm{E}$

2) Nominal stress: $\sigma_{n}=P / S_{o}$ P: Load Value (N), $\mathrm{S}_{0}$ : Initial cross section area of specimen $\left(\mathrm{mm}^{2}\right)$

3) True stress: $\sigma_{t}=\sigma_{n} \cdot(1+\varepsilon), \quad \sigma_{t}$ is valid until the tensile strength of maximum load point $\sigma_{\mathrm{B}}$.

Fig. 2 Experimental setup for X-ray stress measurement in tensile testing 
The measureable range of extension meter is up to $25 \mathrm{~mm}$ deformation in $50 \mathrm{~mm}$ gauge length and maximum strain is $0.5 \mathrm{~mm} / \mathrm{mm}$. SM490 specimens were measurable until just before the fracture point. For SUS316 specimens, we set the range as 50\% strain because the fracture elongation was more than $55 \%$. Fig. 3 shows the schematic diagram of specimen stress-strain curves, uniaxial plane strain model as stress model, and plastic deformation value. The nominal stress and the true stress were calculated by the following equations.

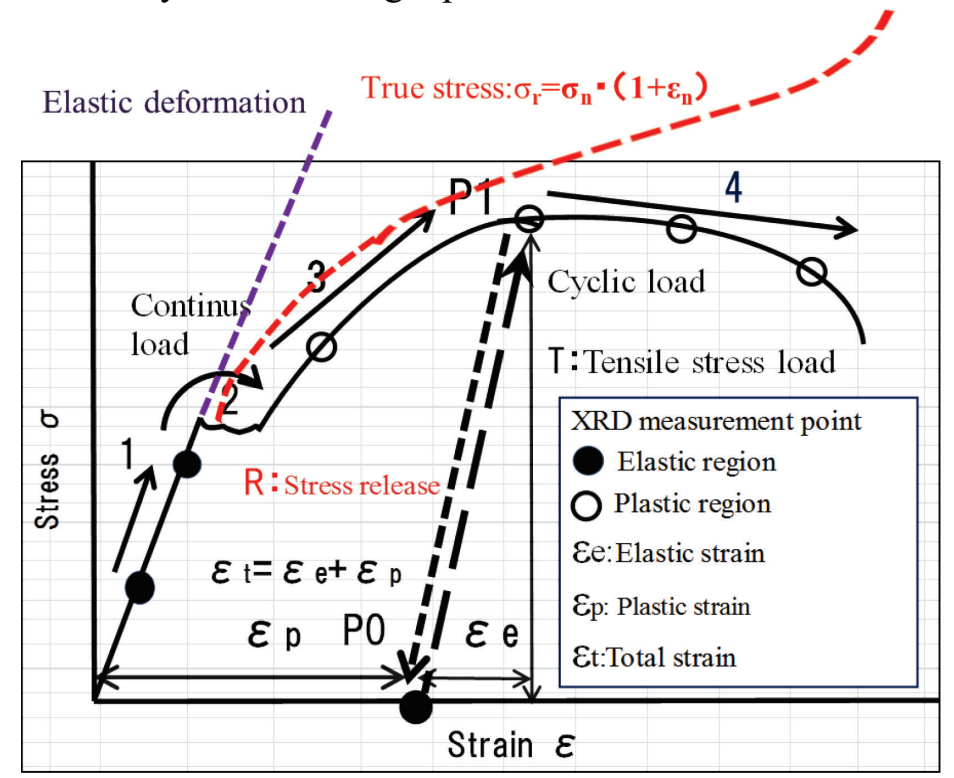

Region

1: Elastic deformation

2: Yielding

3: Hardening area

4: Specimen is necking

and load decreasing

Nominal stress: $\sigma_{\mathrm{n}}=\mathrm{P} / \mathrm{S}_{0}$

Initial cross area: So

$$
\begin{aligned}
& \text { P1 strain } \\
& \varepsilon t: \varepsilon t=\varepsilon \mathrm{e}+\varepsilon p \\
& \varepsilon e: \varepsilon e=\sigma / \mathrm{E}, \\
& \sigma=\mathrm{E} \cdot \varepsilon \mathrm{e} . \\
& \varepsilon p=\varepsilon \mathrm{t}-\varepsilon \mathrm{e} .
\end{aligned}
$$

Fig. 3 The schematic diagram of specimen stress-strain curves

$\operatorname{Sin}^{2} \psi$ method is used for XRD measurement, and $\sin ^{2} \psi$ method is used for $\psi$ goniometer. The applied equipment was Stresstech Oy., X3000. Table 2 shows the measuring specification.

Table 2 Conditions for X-ray stress measurement

\begin{tabular}{|c|c|c|}
\hline Material (JIS) & Carbon steel ( JIS: SM490) & Stainless steel (JIS: SUS316) \\
\hline Characteristic X-ray & $\mathrm{Cr}-\mathrm{K} \alpha$ & $\mathrm{Mn}-\mathrm{K \alpha}$ \\
\hline Diffraction line, hkl & 211 & 152.3 \\
\hline Diffraction angle (deg. ) & 156.4 & 30 \\
\hline Tube voltage (kV) & \multicolumn{2}{|c|}{6.7} \\
\hline Tube current (mA) & (X-ray slit) $\varphi 3.0 \mathrm{~mm}$ \\
\hline Collimator spot size & (2)
\end{tabular}

\section{Experimental Results and Discussion}

\subsection{Measurement Results of Incremental Load Process}

Fig. 4 shows the experimental results of the relationship between XRD measured stress value and strain at each interrupting position in the continuous incremental load test. Stress was measured by XRD after a while from the load tester stopped and load is stable. Since it takes a little while that the load to specimen gets stable when the load tester stopped. The XRD measured stress value was compared with the nominal stress and true stress value. The result showed both SM490 and SUS316 decreased their cross-section areas of specimens when the strain or elongation is increased. Nominal stress values increased a little and drew a smooth curve in plastic region. However, calculated true stress values in effective cross-section area during measurement increased monotonically. Likewise, XRD measured stress value increased monotonically, and this changing rate corresponds with changing rate of true stress. 


\section{(}
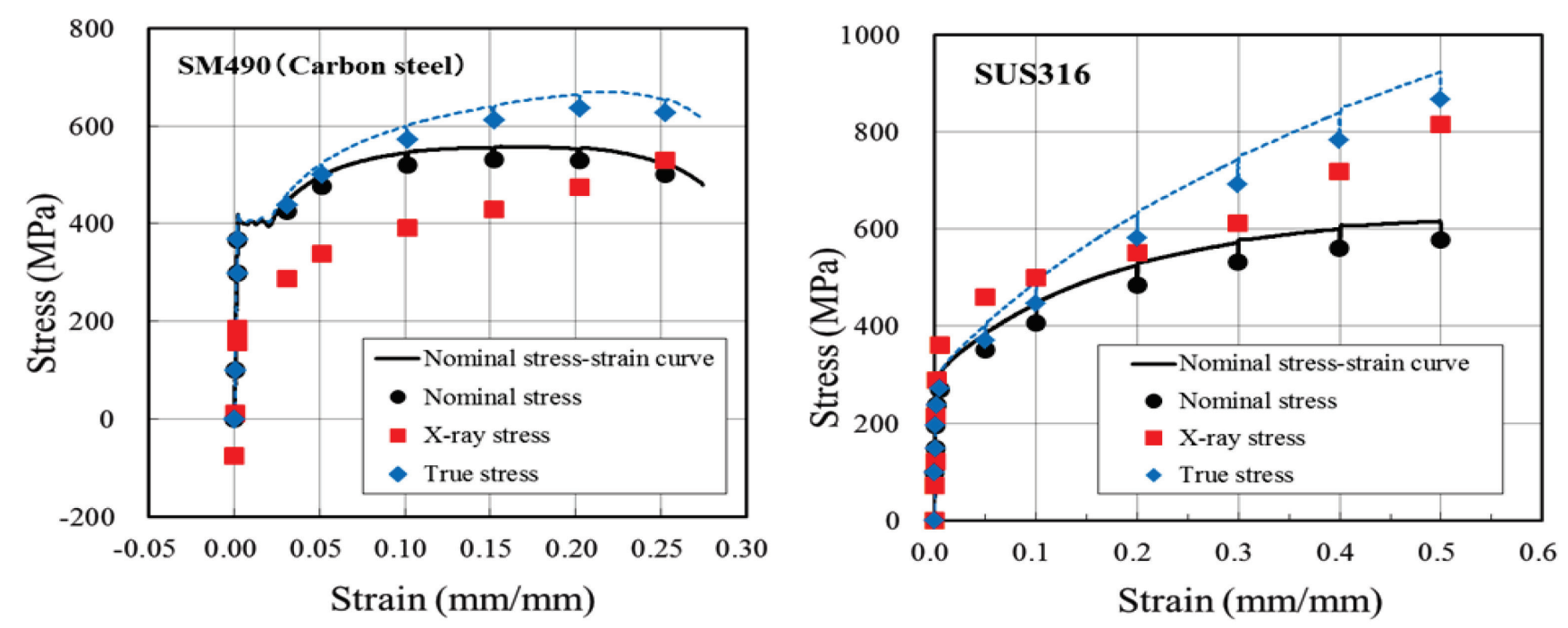

Fig. 4 Stress-strain curve for continuous tensile loading

Stainless steel does not show clear yield point, so we determined its elastic region as up to 150MPa. Fig.5 shows the relationship between XRD measured stress value and the true stress value for each measuring point in elastic and plastic regions. In the case of SM490, the difference between $\sigma_{\mathrm{t}}$ and $\sigma_{\mathrm{x}}$ is about $180 \mathrm{MPa}$. There is the influence of specimen setting condition such as bending moment and specimen surface initial stress conditions. But in this figure, XRD measured stress value and the true stress value shows deep correlation, and the coefficient factor is approximately 1.
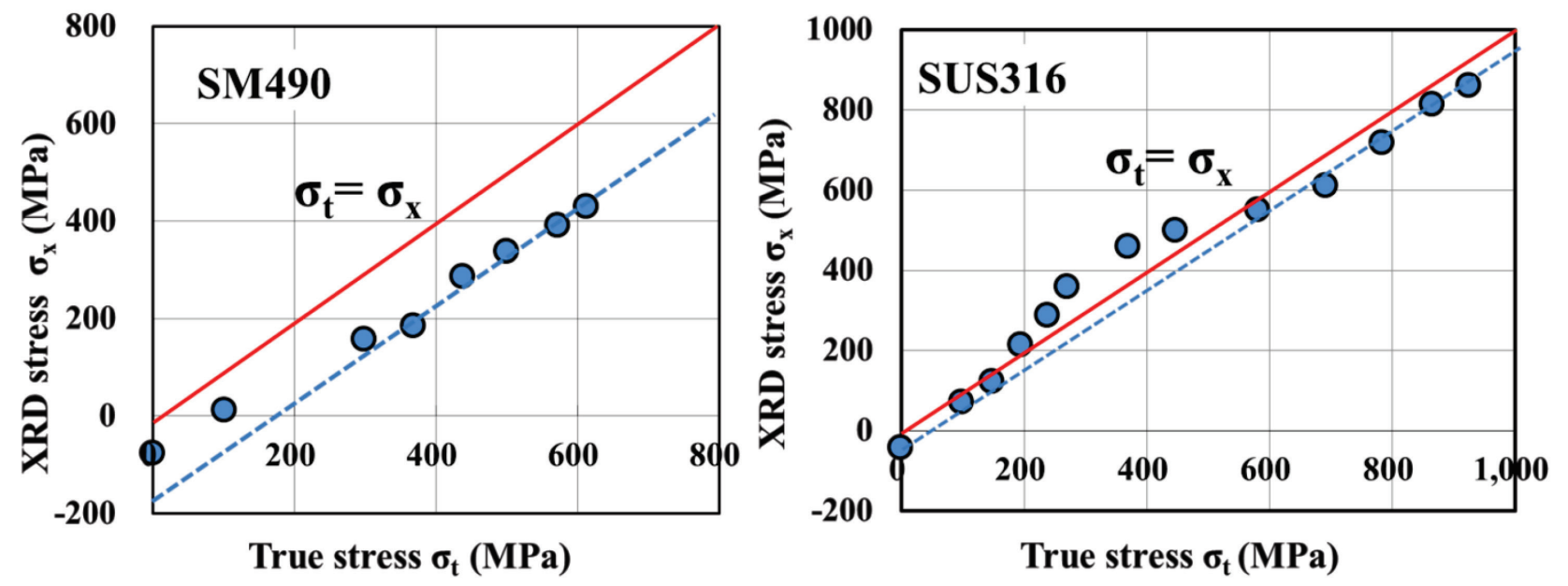

Fig. 5 Relationship between X-ray stress and true stress in continuous tensile lording

On the other hand, case of SUS316, XRD measured stress value was higher than the true stress value in the stress level from $200 \mathrm{MPa}$ of proof stress to $400 \mathrm{MPa}$. We considered that these areas are large work hardening and it is because there was stress distribution difference between both inside and surface of the specimen in the plastic region. Therefore, strain value on the surface of specimen was bigger than its inside when incrementally loaded, so the XRD measured value was higher.

In any case, carbon steel and stainless steel together have the good correlation for the actual-stress and the XRD stress value to the large plastic deformation.

\subsection{Measurement Results of Cyclic Load Process}

In this cyclic load measurement, we stopped tensile test machine and measured the stress by XRD at predefined stress point in elastic region and predefined strain value point in plastic region. After 
measuring, the load was released to level 0 , and we measured XRD stress again. Then the specimen was re-loaded again until next release point, and we measured XRD stress value. This testing flow was repeated for each measuring points. Fig.6 shows the measurement results by XRD stress and applied load value on each extensometer elongation for each measured points.
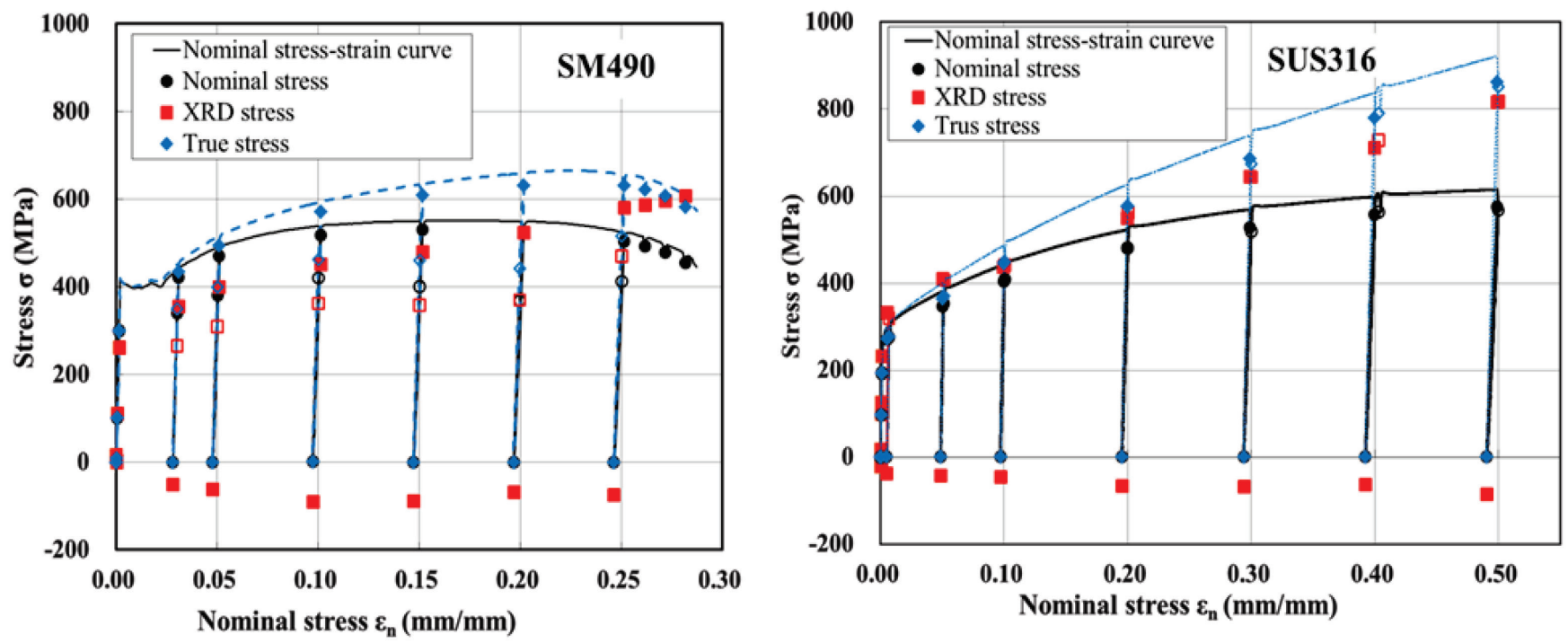

Fig. 6 Stress-strain curve for cyclic tensile loading

Both SM490 and SUS316 showed compressed stress value when loading was released in plastic region. We regarded it as Bauschinger effect by the cause of the stress distribution difference in the specimen cross sections. In the case of SM490, the true stress value over the tensile strength $\sigma_{B}$ is reference data. Since the strain stress on SM490 ingenerates localized neck when the stress exceeds $\sigma_{\mathrm{B}}$, but calculated true stress value from measured localized neck area, the true stress value shall be increased monotonically like XRD measured stress value. Fig.7 shows the relationship between $\sin ^{2} \psi$ and $d$ for XRD measurement results of SUS316 each plastic deformation. Irrespective of the plastic deformation, the both relation shows good linearity correlation. This figure shows the measurement effectivity was confirmed.
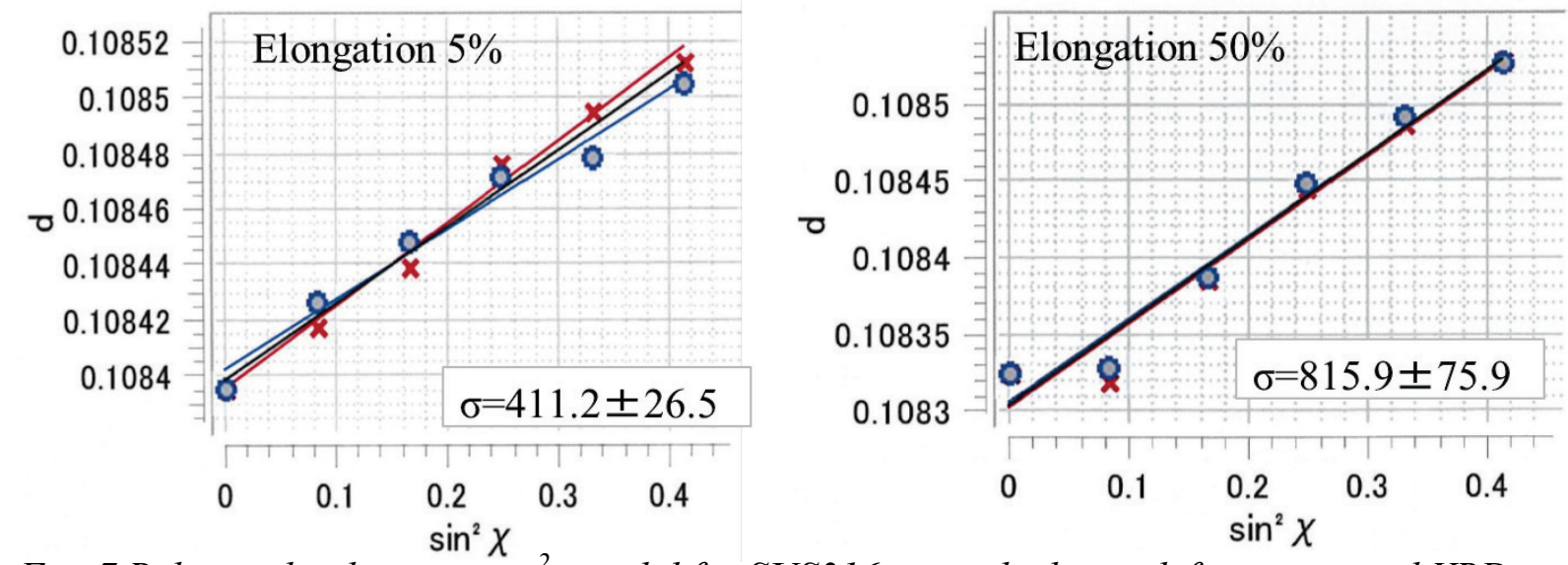

Fig. 7 Relationship between $\sin ^{2} \psi$ and $d$ for SUS316 on each elastic deformation and XRD stress results

Fig. 8 shows the relationship between XRD measured stress value and the true stress value from these measuring results. There are high correlations with XRD stress and the true stress, as same as the case of incremental load process. In the case of SM 490, the difference between $\sigma \mathrm{t}$ and $\sigma \mathrm{x}$ is about 
100MPa. In the case of SUS316, XRD measured stress value was higher than the true stress value on low plastic region near the proof stress as same as incremental load process. However, the stress distribution difference on inside of specimen which occurred by repeating the test got smaller, and it showed deep linear relationship with true stress alongside of incremental load process.
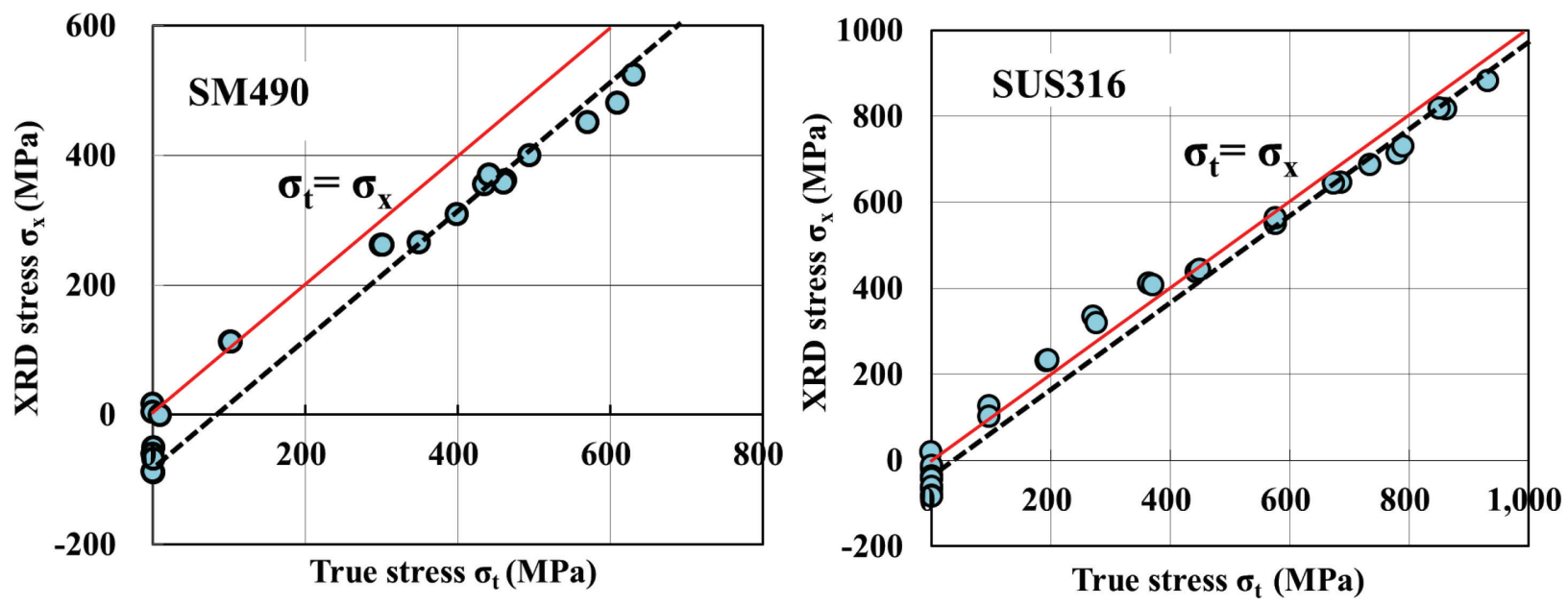

Fig. 8 Relationship between X-ray stress and true strain in cyclic tensile lording

\section{Conclusion}

1) We examined the relationship between the external load stress and XRD measured stress. XRD measured stress can be always shown the real stress value on the material regardless of elastic and plastic deformation.

2) XRD measured values are shown summation total stress value of the internal and external load stress.

3) XRD measurement method is a highly reliable method to evaluate the absolute stress on a material.

4) XRD measured value at the surface neighborhood of material is influenced by its surface condition.

5) The residual stress values vary depending on the measurement methods, and XRD stress values are sometimes different from the strain gauge measured values on the field measurement.

6) It is important to understand the properties of each measurement method well.

7) It is difficult to measure the absolute stress value of components as correctly on site. We have to use suitable and various measurement methods to measure highly reliable value.

\section{References}

[1] JSMS-SD-5-02, "Standard method for X-ray stress measurement", The Society of Materials Science, Japan (2002).

[2] S. Taira, K. Hayashi and N. Urakawa, "X-ray Measurement and Analysis of Residual Stress Induced in Polycrystalline Aluminum by Uniaxial Plastic Deformation", Journal of the Japan Institute of Metals, Vol.35, No.3, pp189-196(1971).

[3] K. Kojima, "Stress Measurement for X-ray", Journal of the Society of Materials Science, Japan, Vol.47, No.6, pp.502-509(1952). 